\title{
Variations of widespread extreme cold and warm days in winter over China and their possible causes
}

\author{
Zhiyan $\mathrm{ZUO}^{2,3^{*}}$, Mingqian $\mathrm{LI}^{1}$, Ning $\mathrm{AN}^{1}$ \& Dong XIAO ${ }^{1}$ \\ ${ }^{1}$ State Key Laboratory of Severe Weather, Chinese Academy of Meteorological Sciences, Beijing 100081, China; \\ ${ }^{2}$ Department of Atmospheric and Oceanic Sciences/Institute of Atmospheric Sciences/IRDR-International Center of Excellence, Fudan \\ University, Shanghai 200348, China; \\ ${ }^{3}$ Collaborative Innovation Center on Forecast and Evaluation of Meteorological Disasters, Nanjing University of Information Science and \\ Technology, Nanjing 210044, China
}

Received January 12, 2021; revised August 19, 2021; accepted August 27, 2021; published online December 2, 2021

\begin{abstract}
The two leading modes of winter surface air temperature (SAT) over China during 1961-2017 are a spatially consistent pattern and a north-south dipole pattern. Based on the two leading modes, the characteristics of the extreme cold and warm days in the two patterns, defined by the standard deviation larger than 1.28 or smaller than -1.28 in the time series of the two leading modes, are analyzed. With the increase of winter SAT during 1961-2017, the number of spatially consistent extreme cold days decreased and their occurrence was restricted to late December to early January, whereas the number of spatially consistent extreme warm days increased significantly in January and February. Global warming is associated with an increase in the spatially consistent extreme warm days and a decrease in spatially consistent extreme cold days, but has little relation to the sum of extreme cold and warm days of either the spatially consistent or north-south dipole pattern. The Siberian High (SH) is the main factor controlling the sum of spatially consistent extreme warm and cold days. The strong (weak) SH before (after) the 1990s corresponds to an increase (decrease) in the sum of the spatially consistent extreme warm and cold days. The occurrences of extreme south-cold-north-warm and extreme south-warm-north-cold days are related to the north-south difference of the SH. When the center of the SH is in mid-high latitudes, the extreme south-warm-north-cold (south-cold-north-warm) days occur more (less) often. During the winters of 1961-2017, the total number of extreme cold and warm days of the north-south dipole pattern changes negligibly. The North Atlantic meridional overturning circulation (AMOC) may be the main factor affecting the sum of the extreme cold and warm days of the two types of SAT pattern in China.
\end{abstract}

Keywords Surface air temperature, Extreme cold days, Extreme warm days, Siberian High, North Atlantic meridional overturning circulation

Citation: Zuo Z, Li M, An N, Xiao D. 2022. Variations of widespread extreme cold and warm days in winter over China and their possible causes. Science China Earth Sciences, 65(2): 337-350, https://doi.org/10.1007/s11430-021-9836-0

\section{Introduction}

Under global warming, the winter surface air temperature (SAT) in China has shown an obvious upward trend in recent decades, corresponding to a significant decrease in the frequency of extreme low temperature events (cold days, cold

\footnotetext{
* Corresponding author (email: zuozhy@fudan.edu.cn)
}

nights, and frost days) over the past 50 years (Wang et al., 2012, 2013; Shi et al., 2019). However, there are significant interdecadal fluctuations in the rising trend of winter surface temperature (Ding et al., 2007, 2014; Liang et al., 2014), characterized by the frequent occurrence of extreme low temperature record-breaking events in northern China in the 21st century. In the 1980s, the frequency of extreme low temperature events was relatively high, mainly in North and southwest 
China. In the 1990s, the frequency of extreme low temperature events was relatively low, and they occurred mainly in Hetao and southern China. After 2000, record-breaking low temperature events occurred frequently in Northeast China. Detailed studies have been conducted on warm winters in China, extreme cold winters in southern China, and on the temperature anomaly and its trigger mechanism in Northeast China (Wang et al., 2007; Hao et al., 2011; Zhang and Qian, 2012; Shen et al., 2013; Miao et al., 2016).

The interdecadal variations of winter SAT and extreme cold and warm events in China are significantly correlated with the interdecadal variations of the East Asian winter monsoon (EAWM). When the EAWM is in a strong phase (before the 1980s and after the start of the 21st century), more extreme cold events occur, whereas, during a weak EAWM phase (from the middle of the 1980s to the 1990s), cold (warm) events occur less (more) frequently in East Asia (He and Wang, 2012; Wang et al., 2012; Wang and Chen, 2014). The EAWM system is related to global atmospheric circulation. The Arctic Oscillation, North Atlantic Oscillation, global and Silk Road teleconnections, Southern Oscillation, El Nino, Madden Julian Oscillation and their different configurations have important impacts on the EAWM from seasonal to interannual and interdecadal timescales (Chen et al., 2014; Yao et al., 2016; Lim and Kim, 2016; Song and $\mathrm{Wu}, 2017,2019)$. Previous studies have reported that the stratosphere-troposphere interaction can also have an important impact on the EAWM and the winter SAT in China (Wang et al., 2009; Chen et al., 2013). Under global warming, snow cover in the middle-high latitudes of Eurasia, Arctic sea ice, and tropical Pacific sea surface temperature are the main drivers of EAWM variability. These factors have an important impact on China's winter SAT by changing the Siberian High (SH), the Ural blocking high, the westerly belt, and the East Asian Trough (Guo, 1994; Kang et al., 2006, 2009; Zhou et al., 2007; Ma et al., 2008; Xiao et al., 2016; Zuo et al., 2018). For example, the rapid reduction of Arctic sea ice after the 1990s corresponds to the frequent occurrence of a blocking high in the Ural Mountains, the deepening of the East Asian Trough, and the enhancement of the SH, which allows polar cold air into mid-latitude Eurasia, leading to the increase of the frequency of persistent low temperature events in northern China after 2000 (Liu et al., 2012; Liang et al., 2014; Mori et al., 2014; Wang and Lu, 2017). The intensity of the SH has been used as an intensity index for the East Asian Winter Monsoon (Gong et al., 2001). A southward outbreak of high-latitude cold air caused by the movement of the SH often leads to anomalously low temperatures, freezing rain and snow, and other disastrous weather in China and across East Asia.

The leading two modes of the winter SAT in China are spatially consistent country-wide mode and a dipole mode with opposing changes in Northeast, Southwest, and South
China (Kang et al., 2006, 2009; Zhu et al., 2007; Wang et al., 2010; Chen et al., 2014). From the mid-20th century to the 1980s, the spatially consistent mode was dominant. The north-south dipole mode had a significant interdecadal change in the mid and late 1990s (Yang and Wu, 2013). After the early 21 st century, the north-south dipole mode became the strongest mode of surface SAT (Huang et al., 2014). Xiao et al. (2017) suggested that the spatially consistent pattern was not significantly correlated with the SAT in other regions, but the north-south dipole pattern showed significant relation to the SAT over mid-high latitude Eurasia at interannual time scales. Zuo et al. (2015) pointed out that in December and January the probability of a persistent warm event decreases when the spatially consistent extreme warm event occurs whereas the probability of a persistent cold event increases after a spatially consistent extreme cold event occurs. Following on from our previous research, this paper analyzes the variation and causes of extreme cold and warm days in winter based on the main spatial modes of the winter SAT. The main scientific problems include: (1) what is the spatial configuration of the extreme warm and cold days in winter? (2) How do these extreme temperature events with a given spatial configuration change with time? (3) What are the factors that drive this spatial configuration change with time? (4) Will global warming increase the number and intensity of temperature extremes during winter in China? (5) What role does the interdecadal variation of the EAWM play?

\section{Data and method}

We use daily SAT data from the National Meteorological Information Center, China Meteorological Administration, with $0.5^{\circ} \times 0.5^{\circ}$ horizontal resolution for 1961-2017. The sea-level pressure, $500 \mathrm{hPa}$ geopotential height and $850 \mathrm{hPa}$ zonal and meridional winds are from JRA-55. For the convenience of calculation, the data for February 29 in leap years are excluded. The SH intensity index used in this paper is defined by Gong and Wang (1999),

$I=\frac{\sum_{n=1}^{2673} P_{n} W_{n} \cos O_{n}}{\sum_{n=1}^{2673} W_{n} \cos O_{n}}$,

where $P_{n}$ is the sea-level pressure at grid point $n, O_{n}$ is the latitude of grid point $n, W_{n}=1$ when $P_{n} \geq 1028 \mathrm{hPa}$, and $W_{n}=0$ when $P_{n}<1028 \mathrm{hPa}$. This index reflects the amount of atmospheric mass accumulated in the atmospheric column per unit area of the high pressure center in the domain $20^{\circ} \mathrm{N}-$ $70^{\circ} \mathrm{N}, 50^{\circ} \mathrm{E}-150^{\circ} \mathrm{E}$ with 2673 grid points. The North Atlantic meridional overturning circulation index used in this paper is downloaded from http://www.pik-potsdam.de/ caesar/ AMOC_slowdown/; the source of the data is the monthly averaged HadISST. Empirical orthogonal function (EOF) 
analysis is used to study the spatiotemporal variation pattern (Jolliffe, 1986).

\section{Spatial pattern of massive extreme cold and warm days and its variations}

To investigate the spatial configuration of extreme cold and warm days at a large scale, EOF analysis is applied to the daily SAT anomaly over China from December to February in winter from 1961 to 2017. Figure 1 shows the spatial distribution and corresponding time series of the first two modes. The first spatial mode (EOF1) of each month in winter shows temperature anomalies of the same sign across China as a whole, with the largest temperature anomalies in Northern Xinjiang and Inner Mongolia. Warm anomalies in February are larger than those in December and January. The second spatial mode (EOF2) is characterized by opposite variations in the north and south. Specifically, when the SAT in North and Northeast China is abnormally warm (cold), southern China is cold (warm) at the same time (hereinafter referred to as the south-cold-north-warm and south-warmnorth-cold patterns). These two modes account for $\sim 50 \%$ of the variance contribution, representing the mode of winter surface temperature anomaly in China generally.

Extreme warm (cold) days are defined using a threshold of $1.28(-1.28)$ standard deviations (exceeding $80 \%$ confidence level) in the corresponding time series in the leading two modes (Zuo et al., 2015). When (1) the value of a day in the EOF 1 corresponding time series is larger (smaller) than 1.28 $(-1.28)$ standard deviations, and (2) if the SAT anomaly on this day is uniform over $>90 \%$ of the grid points in China except the domain $20^{\circ} \mathrm{N}-35^{\circ} \mathrm{N}, 77^{\circ} \mathrm{E}-104^{\circ} \mathrm{E}$, it is considered as a spatially consistent extreme warm (cold) day. When (1) the value of a day in the EOF2 time series is larger (smaller) than $1.28(-1.28)$ standard deviations, and (2) if the SAT at $>70 \%$ of the grid points in the northern domain $\left(41^{\circ} \mathrm{N}-54^{\circ} \mathrm{N}\right.$, $115^{\circ} \mathrm{E}-136^{\circ} \mathrm{E}$ ) exhibits opposite anomalies to the SAT over $>70 \%$ of the grid points in the southern domain $\left(18^{\circ} \mathrm{N}-28^{\circ} \mathrm{N}\right.$, $102^{\circ} \mathrm{E}-121^{\circ} \mathrm{E}$ ) on this day it is defined as an extreme southwarm-north-cold (south-cold-north-warm) day.

These criteria give 385 extreme consistent warm days, 430 extreme consistent cold days, 328 extreme south-warmnorth-cold days, and 255 extreme south-cold-north-warm days out of the 5130 winter days for 1961-2017. Table 1 shows the number of extreme days in each month. The total number of the two types of extreme cold and warm days in February is greater than in December and January (38 days more than in December and 52 days more than in January). In December and February, the probability of spatially consistent extreme cold and warm days is significantly higher than that of north-south dipole extreme cold and warm days, and this feature is more obvious in February. The probability of spatially consistent extreme cold and warm days is about twice that of north-south dipole extreme cold and warm days. The number of extreme south-cold-north-warm days is least in December (71 days) and February (74 days), and there are more than 100 days of other types of extreme cold and warm days. In January the probability of extreme cold and warm days is the same for the two types.

Figure 2 shows the spatial distribution of the difference between the SAT on extreme warm/cold days and the climatological SAT for 1961-2017. The distribution is consistent with the spatial distribution of the EOFs (Figure 1). For the spatial coherent extreme cold and warm days, apart from an area near the Qinghai Tibet Plateau, the anomalies in most of China exceed the $95 \%$ confidence level. For the extreme north-south dipole extreme days, the SAT anomalies in Northeast China and south of the Yangtze River exhibit opposite characteristics that exceed the $95 \%$ confidence level. The SAT anomalies in extreme warm/cold days in February are more severe than in December and January.

The time evolution of the two types of extreme cold and warm days is shown in Figure 3. The number of spatially consistent extreme cold days decreased gradually before 2000, and the occurrence days approached the middle of January, but increased slightly after 2000. The spatially consistent extreme warm days show an obvious increasing trend, which occurred mainly in the first 10 days of December before 1990 and increased significantly in February after 1990. That is, the spatially consistent extreme warm days are more likely to occur in the second half of winter from mid-January to February with global warming. The extreme south-warm-north-cold days occurred more frequently before 1980 and after 2000 than during 1980-2000. They occurred mainly in January during 1980-2000 but mainly in December and February before 1980 and after 2000. The extreme south-cold-north-warm days occurred more frequently during 1980-2000, and most of them occurred in January. The EAWM was generally stronger before

Table 1 Extreme warm or cold days for 1961-2017

\begin{tabular}{cccccc}
\hline Extreme cold/warm days & $\begin{array}{c}\text { Spatially consistent } \\
\text { warm days }\end{array}$ & $\begin{array}{c}\text { Spatially consistent } \\
\text { cold days }\end{array}$ & $\begin{array}{c}\text { South-warm-north- } \\
\text { cold days }\end{array}$ & $\begin{array}{c}\text { South-cold-north- } \\
\text { warm days }\end{array}$ & $\begin{array}{c}\text { Total } \\
\text { December }\end{array}$ \\
January & 117 & 155 & 115 & 11 & 71 \\
February & 116 & 107 & 102 & 110 & 458 \\
Total & 152 & 168 & 328 & 74 & 255 \\
\hline
\end{tabular}


Zuo Z, et al. $\quad$ Sci China Earth Sci $\quad$ February (2022) Vol.65 No.2
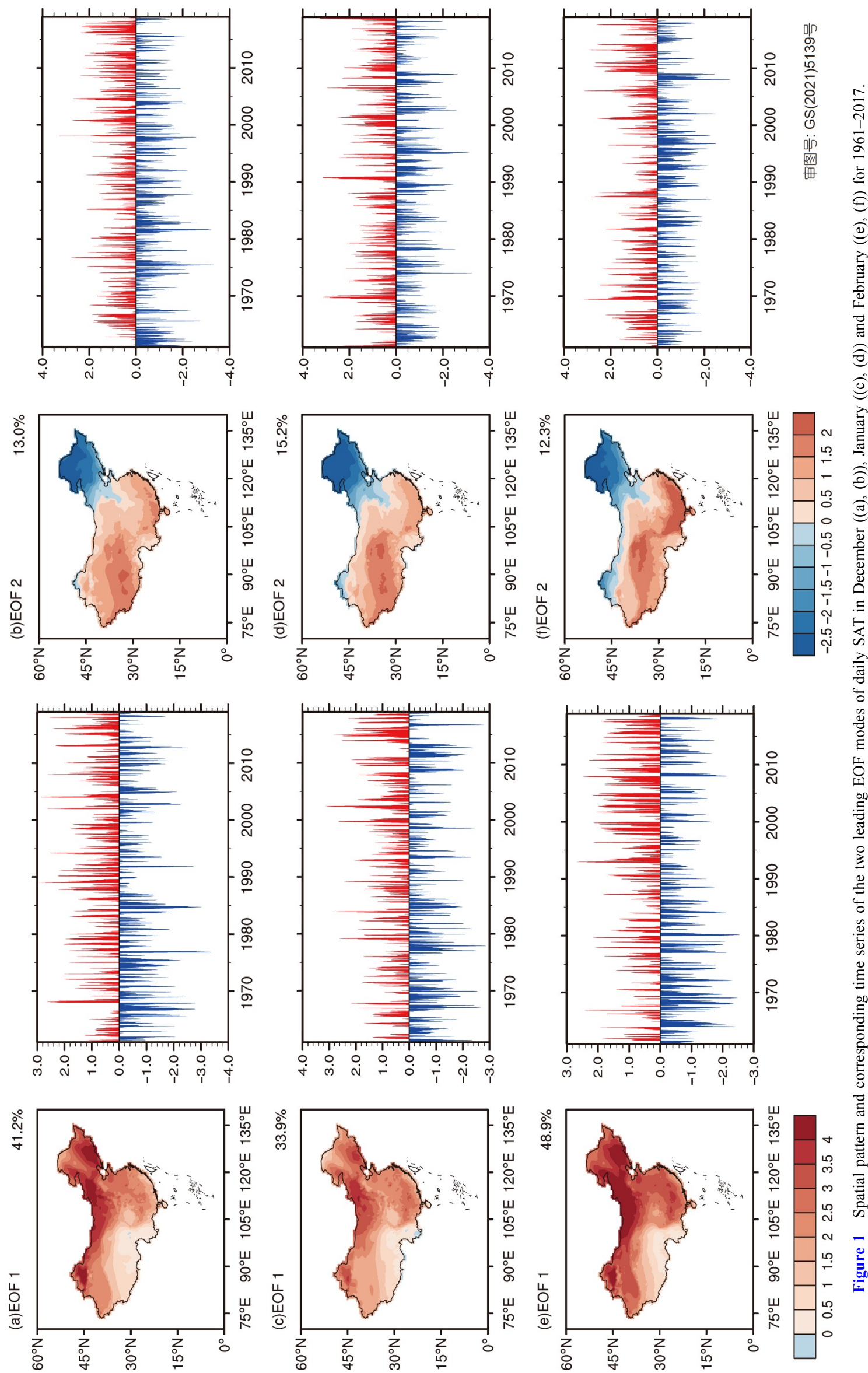

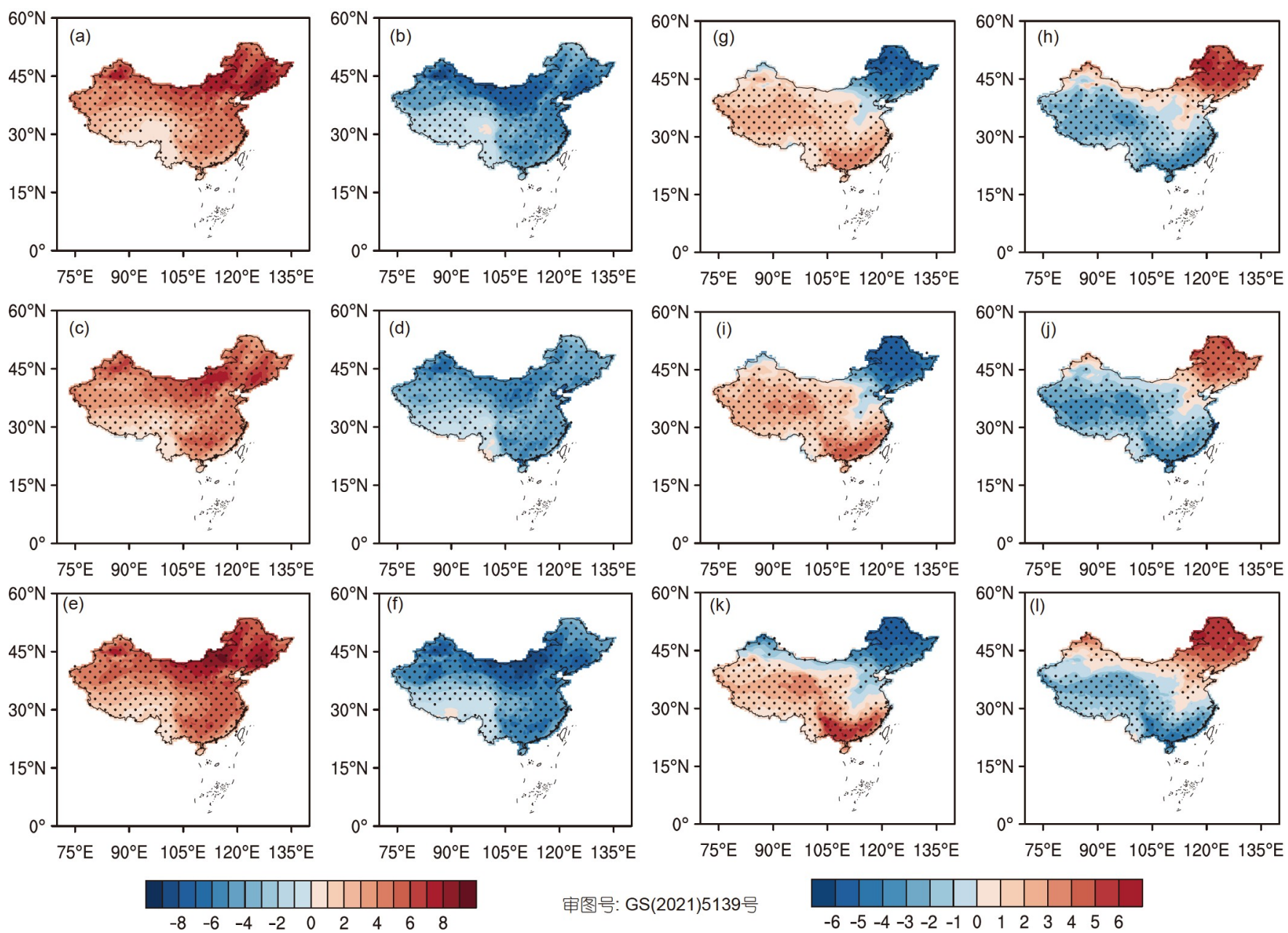

审图号: GS(2021)5139무

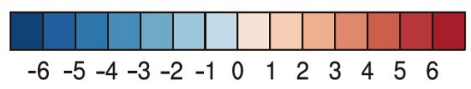

Figure 2 Spatial distribution of the difference between the SAT in the extreme warm/cold days and the climatological SAT for 1961-2017 in December ((a), (b), (g), (h)), January ((c), (d), (i), (j)) and February ((e), (f), (k), (l)) (unit: $\left.{ }^{\circ} \mathrm{C}\right)$, for the ((a)-(f)) spatially consistent extreme warm/cold days and ((g)-(l)) extreme north-south dipole days. Dots indicate the confidence level exceeds $95 \%$.

1980 and after 2000 than during 1980-2000. This suggests that the north-south dipole extremes days are related to the intensity of the EAWM. In the strong EAWM years, the extreme south-warm-north-cold days are more likely to occur in December and February, whereas in the weak EAWM years, the extreme south-cold-north-warm days are more likely to occur in January.

To discuss the interdecadal variation and trend of the two kinds of extreme cold and warm days, the 11-year running number of occurrence days for the two types are shown in Figure 4. The number of spatially consistent extreme warm days has increased in recent decades, while the number of spatially consistent cold days has decreased. The north-south dipole extreme days show obvious interdecadal variation. Before the 1990s, the number of spatially consistent extreme cold (warm) days decreased (increased) significantly, but after 2000, the number of extreme spatially consistent cold (warm) days increased (decreased) slightly, but remained less than (more than) the number before the 1990s. The increase of spatially consistent extreme cold days after 2000 corresponds to the appearance of the "cold Eurasia warm Arctic" mode in the Northern Hemisphere at this time. The number of extreme south-warm-north-cold days is lower from the 1980s to the mid-1990s than before the 1980s and after the mid-1990s, whereas the number of south-coldnorth-warm days increased significantly after the 1980s and decreased after 2000, showing an obvious interdecadal change. The EAWM was weak from the 1980s to the end of the 20th century and the beginning of the 21 st century. After the beginning of the 21 st century, the EAWM strengthened again. The changes of the extreme south-warm-north-cold (south-cold-north-warm) days and the EAWM generally have the same (opposite) phase. The change of the EAWM intensity directly affects the occurrence of extreme cold and warm days in China, but does not reflect the change in the spatial configuration of the widespread extreme cold and warm days. That is to say, when the EAWM is stronger, there are more extreme cold days, but we do not know whether they are extreme south-warm-north-cold days or spatially consistent extreme cold days. The EAWM path may be an 


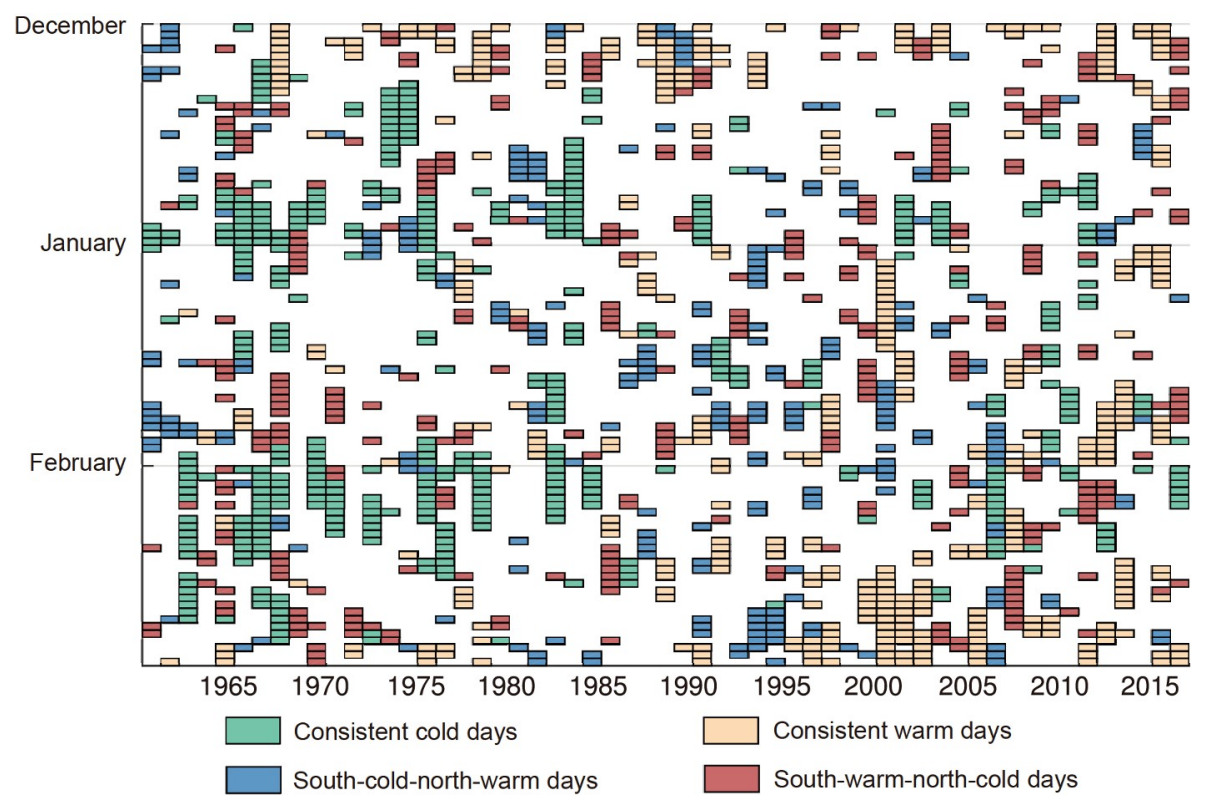

Figure 3 Time evolution of the extreme warm/cold days. Green rectangles are spatially consistent extreme cold days, yellow rectangles spatially consistent extreme warm days, blue rectangles extreme south-cold-north-warm days and red rectangles extreme south-warm-north-cold days.
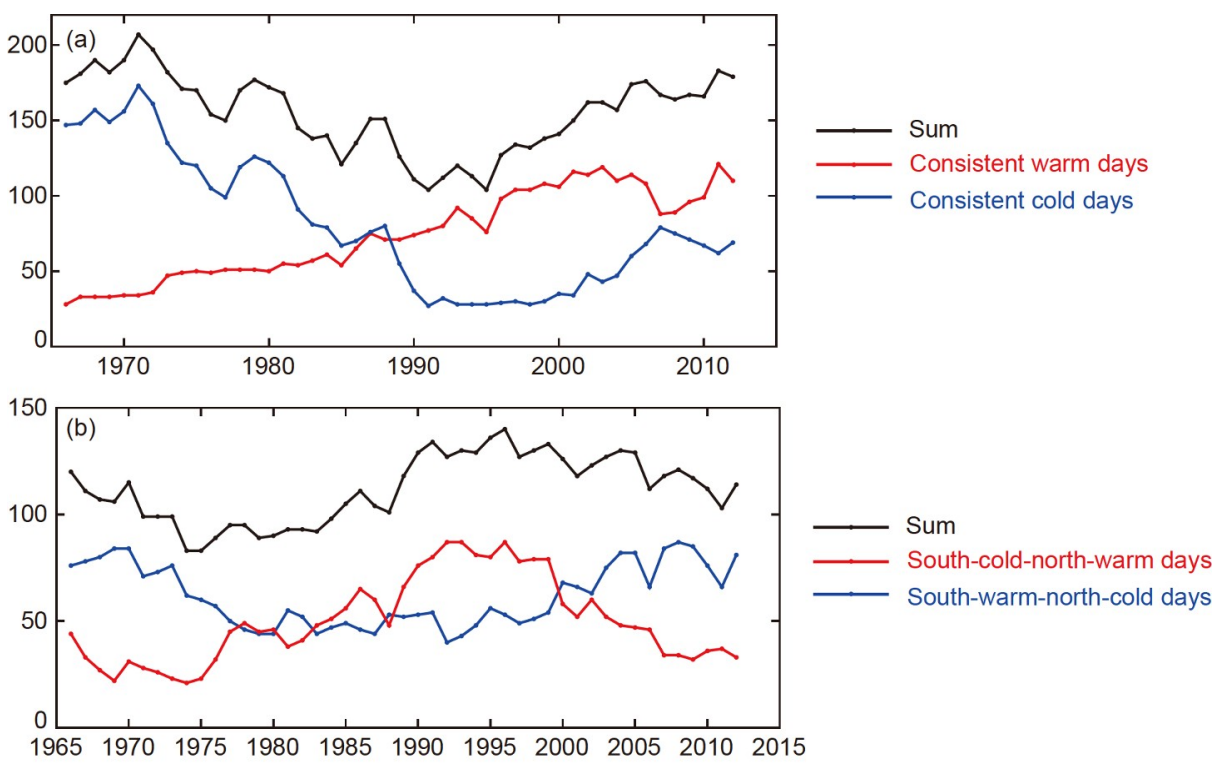

Figure 4 Eleven-year running time series of the (a) spatially consistent extreme warm (red line) and cold (blue line) days, (b) south-warm-north-cold (blue line) and south-cold-north-warm (red line) days for 1961-2017. The black line in (a) is the sum of the spatially consistent extreme warm and cold days and the black line in (b) is the sum of the extreme south-warm-north-cold days and south-cold-north-warm days.

important factor (Wang and $\mathrm{Lu}, 2017$ ). For example, when the EAWM is strong and the path is southward, this favors extreme south-cold-north-warm days. The spatially consistent extreme cold days do not require such a specific atmospheric circulation pattern.

\section{Large-scale atmospheric circulation related to the two types of extreme warm/cold days}

Figure 5 shows the atmospheric circulation anomalies with respect to the climatology for the spatially consistent extreme warm/cold days. The $1028 \mathrm{hPa}$ pressure line is used as the reference for the extent of the SH in winter (Gong and Wang, 1999). When spatially consistent extreme warm days occur, the whole Eurasian continent is controlled by negative anomalies of sea-level pressure (SLP) (Figure 5a). The center of the negative anomalies is located in Inner Mongolia of China and Mongolia, and negative anomalies control China except for parts of Southwest China. The distribution of SLP anomaly in the spatially consistent extreme cold and warm days is almost the opposite (Figure 5b). The whole 

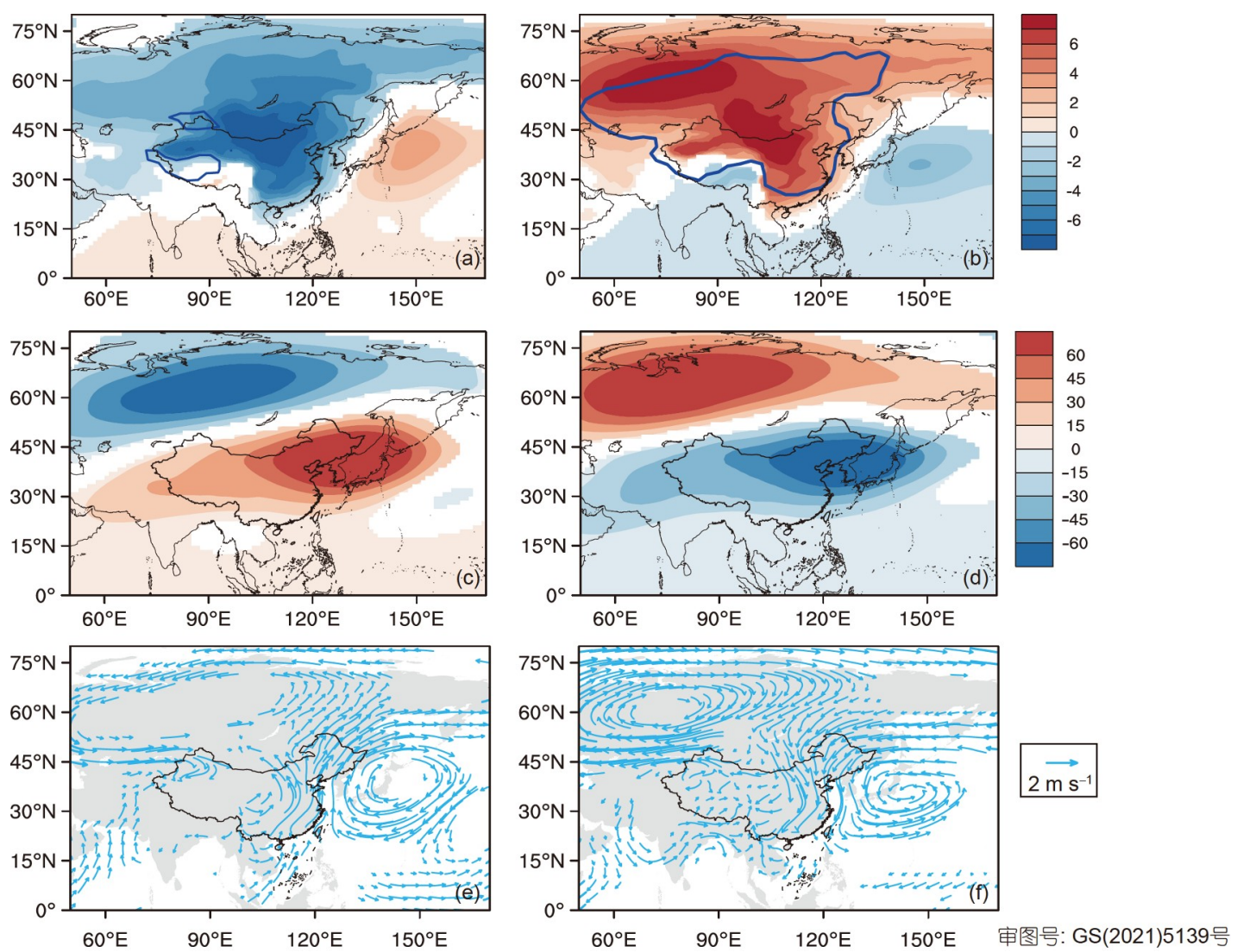

Figure 5 Composite difference of the sea level pressure ((a), (b); unit: hPa), $500 \mathrm{hPa}$ geopotential height ((c), (d); unit: gpm) and $850 \mathrm{hPa}$ horizonal winds ((e), (f); unit: $\mathrm{m} \mathrm{s}^{-1}$ ) between the spatially consistent extreme warm days ((a), (c), (e) or cold days ((b), (d), (f)) and the climatology. The blue lines in (a) and (b) denote the $1028 \mathrm{hPa}$ isobar. Only the areas of sea level pressure, geopotential height and wind differences exceeding the $95 \%$ confidence level are shown with colors and arrows.

Eurasian continent is basically controlled by positive SLP anomaly when spatially consistent extreme cold days occur. There is also a center of positive anomalies in Inner Mongolia of China and Mongolia. The difference is that there is a positive anomaly center in western Siberia when the spatially consistent extreme cold days occur. Moreover, the $1028 \mathrm{hPa}$ pressure line has a wide range, covering $90^{\circ}$ of longitude from east to west and $\sim 40^{\circ}$ of latitude from north to south, including most of China. This kind of SLP field can be clearly connected with the spatially consistent extreme cold days. That is to say, the strong continental cold high leads to sharp cooling over China, resulting in the occurrence of the spatially consistent extreme cold days. This strong cold high not only has an abnormal center in China and Mongolia, but also an anomalous cold high center in West Siberia at higher latitudes. In the spatially consistent extreme warm days, the range of the $1028 \mathrm{hPa}$ pressure line is very small and there is an anomalous cyclonic circulation in Siberia and an anomalous anticyclonic circulation near the Sea of Japan at 850 $\mathrm{hPa}$ (Figure 5e). As a consequence, an anomalous warm southerly airflow dominates the lower troposphere over China, leading to the extreme high temperatures over most of China. In the spatially consistent extreme cold days (Figure $5 \mathrm{f}$ ), the $850 \mathrm{hPa}$ atmospheric circulation is effectively op- posite to that of the spatially consistent extreme warm days. There is an anomalous cyclonic circulation on the east side of China and a strong anomalous anticyclonic circulation in West Siberia. The zonal flow in the middle and high latitudes is anomalously weak. As a consequence, the cold air in the high latitudes intrudes southward to China leading to extreme low temperatures there. When the spatially consistent extreme warm days occur (Figure 5c), there are negative anomalies of $500 \mathrm{hPa}$ geopotential height over mid-high latitude Eurasia but positive anomalies over mid-low latitude Eurasia. The meridional difference of the $500 \mathrm{hPa}$ geopotential height is anomalously small, restricting the meridional trough/ridge activity. In the spatially consistent extreme cold days, the geopotential height anomalies are the opposite (Figure 5d), positive over northern Eurasia and negative over southern Eurasia. The meridional trough/ridge system is deepened; the anomalously strong and deep East Asian trough directs the cold descending air in Siberia southward, so that northerly airflow prevails in the middle troposphere over China, resulting in extreme low temperatures.

The circulation of the extreme north-south dipole warm/ cold days is significantly different from that in the spatially consistent extreme warm/cold days. Over mid-high latitude Eurasia, the distribution of sea-level pressure anomalies in the 
extreme south-warm-north-cold days is similar to that of the spatially consistent extreme cold days, except that the positive center of SH anomalies is shifted slightly eastward (Figure 6a). Positive anomalies also cover Northeast China, but negative anomalies dominate the rest of China. The $1028 \mathrm{hPa}$ line covers most of Eurasia north of $40^{\circ} \mathrm{N}$. Anomalous high pressure controls northern China, whereas southern China is still controlled by the northward airflow from the warm ocean. The SLP anomalies for extreme south-cold-north-warm days are basically opposite to those for extreme south-warm-northcold days (Figure 6b). Northeast China and mid-high latitude Eurasia are covered by negative anomalies, whereas the center of positive anomalies is located in western China. The 1028 $\mathrm{hPa}$ line covers the regions around western China. Thus, the continental high pressure is anomalously weak and the center is located mainly in the areas around western China. Regions with high (low) pressure have anomalously low (high) temperature, indicating the stable relation between the pressure and temperature field at the surface.

The $850 \mathrm{hPa}$ winds show anomalously strong zonal circulation in mid-high latitude Eurasia on extreme north-south antiphase days. In extreme south-warm-north-cold days (Figure 6e), there is anomalous easterly airflow in mid-high latitude Eurasia, with moderate anomalous northerlies bringing cold air southward to Northeast China. Southern China is still controlled by the warm airflow. On extreme south-cold-north-warm days (Figure 6f), the negative temperature anomalies in southern China are caused by the abnormal northwesterly airflow. The high temperature anomalies in Northeast China are the consequence of the abnormal westerlies over mid-high latitude Eurasia restricting cold airflow southward to Northeast China. The potential height field at $500 \mathrm{hPa}$ exhibits a "+ - +" pattern of anomalies and the intensity decreases from north to south successively in the extreme south-warm-north-cold days. That is, the meridional circulation is anomalously strong in mid-high latitudes, sending cold air southward to northern China while the warm high system is also anomalously strong in south China, leading to the anomalously high temperature in south China. The circulation anomalies on extreme south-cold-north-warm days are basically opposite to those of the extreme south-warm-north-cold days (Figure 6d). The $500 \mathrm{hPa}$ geopotential height exhibits a "- + -" pattern from north to south. Negative geopotential height anomalies control mid-high latitude Eurasia and south China whereas positive anomalies cover the regions around Mongolia; this inhibits southward flow of cold air to the north of China and northward flow of warm air to the south of China.

There is a significant interdecadal change in the occurrence of the extreme north-south dipole cold/warm days (Figure 4). During 1985-1995, there were more extreme south-cold-north-warm days and fewer extreme south-warm-
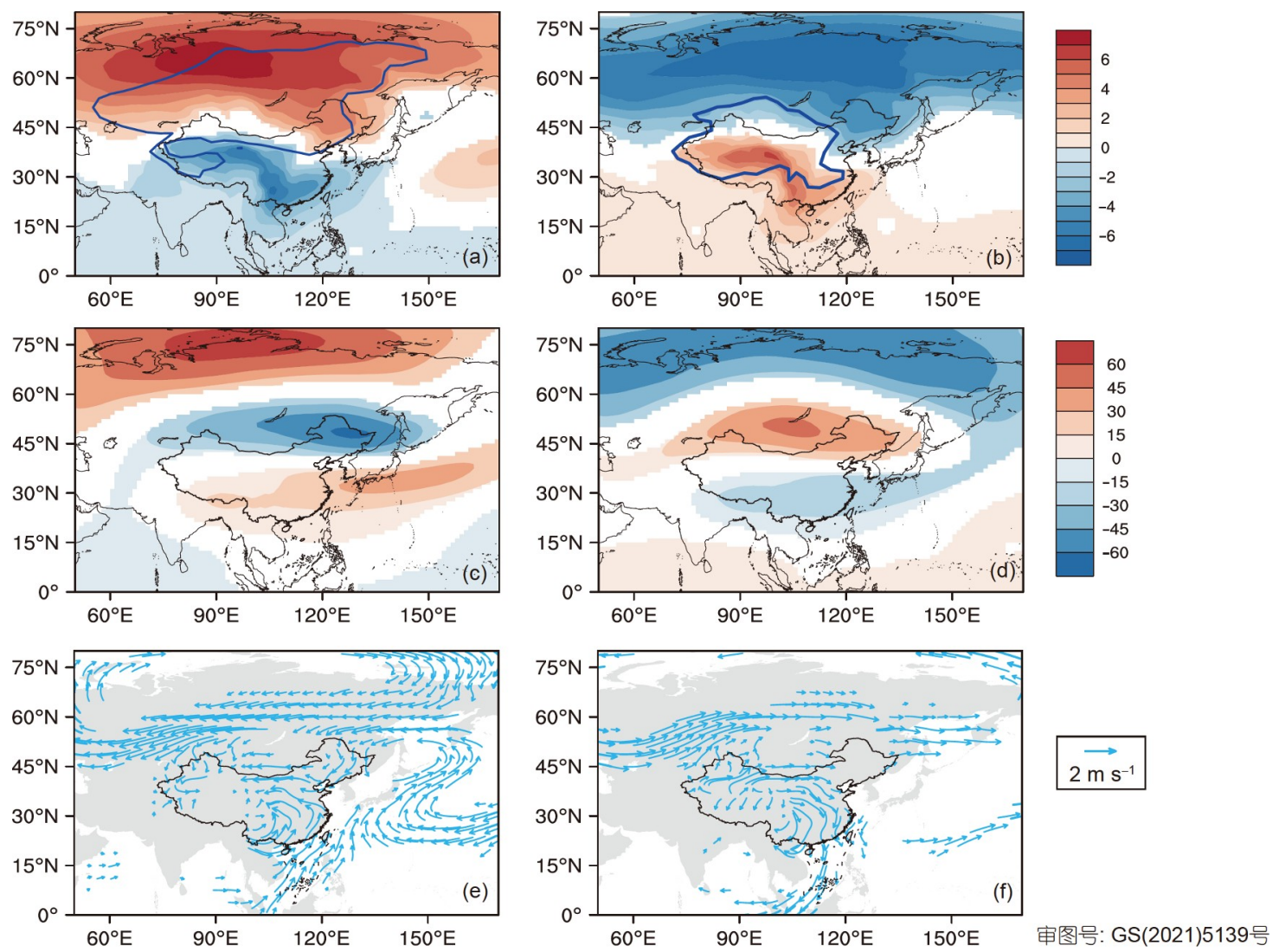

Figure 6 Same as Figure 5 but for the extreme south-warm-north-cold days ((a), (c), (e)) and extreme south-cold-north-warm days ((b), (d), (f)). 
north-cold days. The situation reversed during 2005-2015. Figure 7 shows the composite difference of the SLP between extreme north-south dipole warm/cold days in the two periods and the climatology. The anomalous circulation intensity is weaker (Figure 7a, 7d) when there are fewer northsouth dipole extreme days (Figure 4) than when there are more north-south dipole extreme days (Figure 7b, 7c). Although the anomalous SLP in Northeast China during 19851995 (Figure 7a) is greater than during 2005-2015 (Figure $7 \mathrm{~b}$ ), the positive anomaly in mid-high latitude Eurasia is stronger and the negative anomaly from Western to southern China is more significant during 2005-2015. Therefore, the frequency of extreme south-warm-north-cold days is higher during this period. Similarly, the negative anomaly in midhigh latitude Eurasia corresponding to the occurrence of the extreme south-cold-north-warm days during 1985-1995 (Figure 7c) is stronger than that during 2005-2015 (Figure $7 \mathrm{~d}$ ), which means that the frequency of the extreme southcold-north-warm days during 1985-1995 is higher. In addition, the 11-year average SLP anomalies (Figure 7e, 7f) of the two periods have opposite characteristics. During 19851995, a positive SLP anomaly dominates most of China and negative anomalies dominate the mid-high latitudes (Figure $7 \mathrm{e})$, leading to the anomalously high surface temperature in China. During 2005-2015, the meridional difference is significantly enhanced and southern China is dominated by the negative anomaly (Figure 7f), which favors anomalously low temper temperatures over Northeast China.

\section{The Siberian High and the two types of widespread extreme warm/cold days}

The above analysis suggests that the changes of the two types of extreme warm/cold days are closely related to the SH. The spatially consistent extreme warm days are associated with an anomalously weak $\mathrm{SH}$, and spatially consistent extreme cold days correspond to an anomalously strong SH with the 1028 $\mathrm{hPa}$ pressure line covering most of Eurasia. The extreme south-warm-north-cold days correspond to an anomalously strong SH, but the $1028 \mathrm{hPa}$ line mainly controls the mid-high latitudes. The extreme south-cold-north-warm days are associated with anomalously high pressure near the west of China and the $1028 \mathrm{hPa}$ line is mainly located in southwestern China. We calculate the SH intensity index according to the definition of Gong and Wang (1999), for the whole Eurasian continent $\left(20^{\circ} \mathrm{N}-70^{\circ} \mathrm{N}, 50^{\circ} \mathrm{E}-150^{\circ} \mathrm{E}\right)$, for mid-high latitude Eurasia $\left(40^{\circ} \mathrm{N}-70^{\circ} \mathrm{N}, 50^{\circ} \mathrm{E}-150^{\circ} \mathrm{E}\right)$ and for low latitude Eurasia $\left(20^{\circ} \mathrm{N}-40^{\circ} \mathrm{N}, 50^{\circ} \mathrm{E}-150^{\circ} \mathrm{E}\right)$. In addition, the spatially consistent extreme warm days generally show a linear increasing trend, which indicates that the change of the spatially consistent extreme warm days may be the result of global warming. Figure $8 \mathrm{a}$ shows the 11 -year running mean time series of regional average winter SAT over China and 11-year running number of the spatially consistent extreme warm days. The two time series exhibit quite similar characteristics, suggesting the occurrence of the consistent extreme warm days may be the consequence of the continuous warming over China. The warming is mainly attributed to the increase of greenhouse gases (Zuo et al., 2018). The warming also leads to the decrease of the extreme consistent cold days during the 1960s to 1990s (Figure 8b). The SH was in a weak phase during the 1960s to 1990 s, which reduces the number of the spatially consistent extreme cold days considerably during this period. The SH pressure began to rise after the 1990s and the spatially consistent extreme cold days also show a weak increasing trend after 2000, but the increasing trend is much weaker than that of the SH. The warming caused by the greenhouse gases still plays an important role in reducing the occurrence of spatially consistent extreme cold days. Figure $8 \mathrm{~b}$ shows that the sum of the spatially consistent extreme cold and warm days exhibits the same interdecadal variation characteristics as the $\mathrm{SH}$, indicating that the $\mathrm{SH}$ basically determines the total occurrence frequency of the sum of the spatially consistent extreme cold and warm days. The increasing thermal effect of greenhouse gases increases the number of spatially consistent extreme warm days and decreases the number of spatially consistent extreme cold days, but does not affect their sum. The total number of the spatially consistent extreme cold and warm days is determined mainly by the SH intensity. A positive phase SH corresponds to more spatially consistent extreme temperature events, whereas the negative phase $\mathrm{SH}$ is associated with fewer spatially consistent extreme temperature events. The thermal effect of greenhouse gases only changes the ratio of the numbers of extreme cold and warm days. The increase of greenhouse gases tends to increase the number of spatially consistent extreme warm days in February and decrease the number of spatially consistent extreme cold days in December and February, but its effect on the total occurrence frequency of the extreme consistent cold and warm days is small.

The SH intensity is significantly related to the sum of the spatially consistent extreme cold and warm days. The $\mathrm{SH}$ located in mid-high latitude Eurasia is accompanied by extreme south-warm-north-cold days and the SH located in midlow latitude Eurasia is accompanied by extreme south-coldnorth-warm days. The characteristics of the time evolution of the extreme south-cold-north-warm days are the opposite of those of the extreme south-warm-north-cold days. The difference between the SH intensity index for mid-high latitude Eurasia and that for mid-low latitude Eurasia is calculated to represent the meridional change of the SH center. A large north-south difference means that the SH center is mainly located in mid-high latitudes. A small north-south difference means that the SH intensity changes little with latitude.

Figure 9a shows the time series of the north-south differ- 

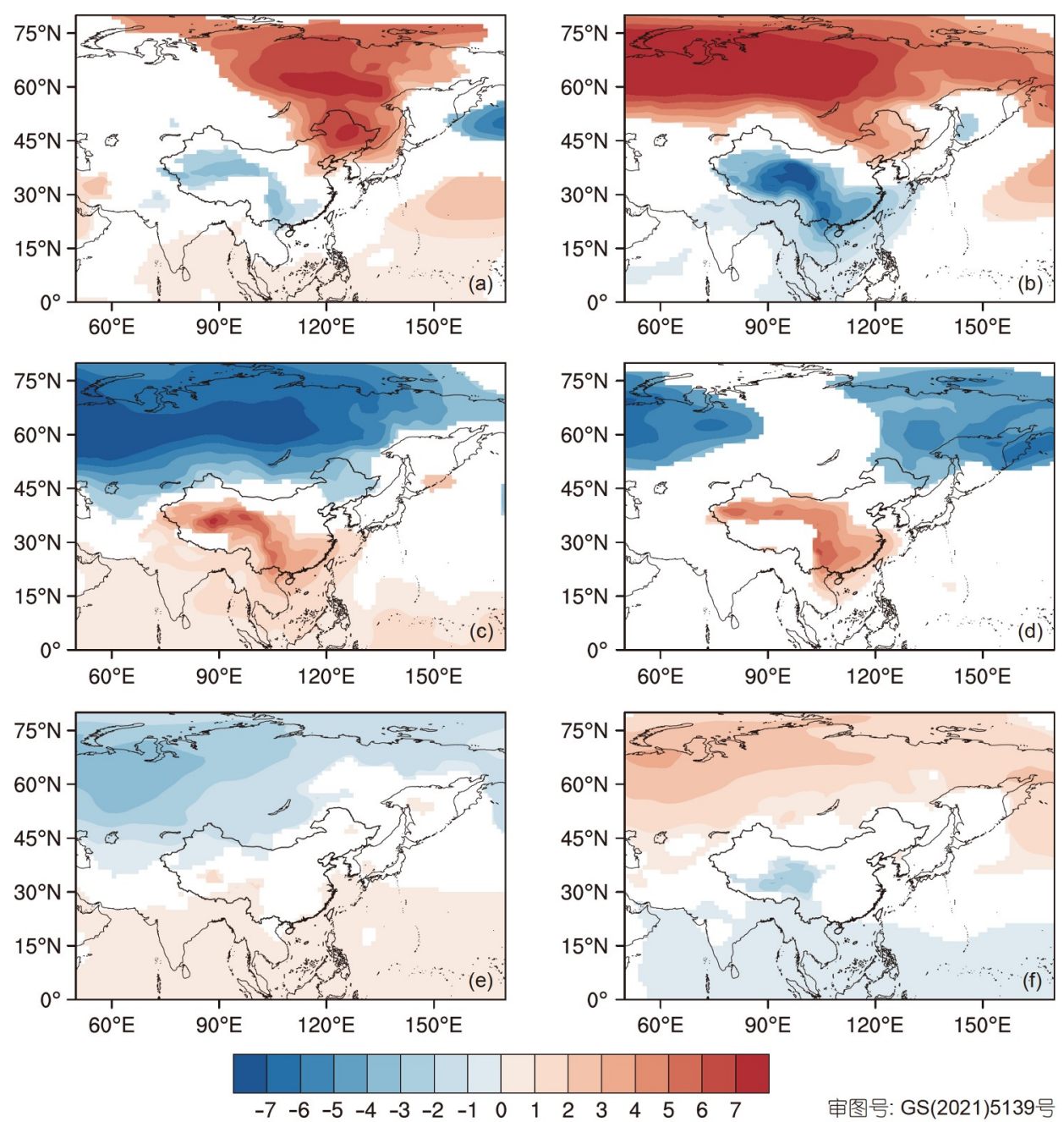

审图号: GS(2021)5139므

Figure 7 Composite difference of the SLP (unit: hPa) with respect to the climatology for the extreme south-warm-north-cold days during 1985-1995 (a) and during 2005-2015 (b), (c), (d) same as (a), (b) but for the south-cold-north-warm days, the 11-year running mean SLP anomalies during 1985-1995 (e) and during 2005-2015 (f). Only the areas of SLP differences exceeding the 95\% confidence level are shown with colors.

ence of the SH and the extreme south-cold-north-warm days. Before the 1990s, the decrease in the north-south difference of the SH corresponds to a southward shift of the center position. Also, the extreme south-warm-north-cold days exhibit a decreasing trend while the extreme south-cold-northwarm days show an increasing trend. After the 1990s, the north-south difference of the $\mathrm{SH}$ increased gradually, corresponding to a northward shift of the SH center. At this time, the extreme south-warm-north-cold days show an increasing trend while the extreme south-cold-north-warm days show a decreasing trend. This suggests that the north-south position of the SH center is the key factor affecting the occurrence of the extreme north-south dipole warm/cold days.

In conclusion, the $\mathrm{SH}$ is the main factor controlling the number of extreme cold and warm days in China, whereas global warming only changes the ratio of extreme cold and warm days. The weakening SH before the 1990s corresponds to a decreasing sum of the spatially consistent extreme warm and cold days, whereas the strengthening SH after the 1990s corresponds to an increasing sum of the spatially consistent extreme warm and cold days. The north-south position of the $\mathrm{SH}$ center is the key factor determining the ratio of the extreme north-south dipole warm/cold days. The SH center in mid-high latitudes corresponds to an increase of the extreme south-warm-north-cold days and a decrease of the extreme south-cold-north-warm days, whereas the reverse is true when the $\mathrm{SH}$ is located farther south. The north-south movement of the $\mathrm{SH}$ center has generally an equivalent effect on the extreme south-warm-north-cold and the extreme south-cold-north-warm days. Thus, it has little effect on the total number of extreme south-warm-north-cold and southcold-north-warm days. In other words, the total number of the extreme south-north dipole cold and warm days remains basically unchanged without other external forcing factors. The increasing trend of SH intensity after the 1990s is obviously more rapid than the decreasing trend before the 1990s. Consequently, the increasing trend of the total number of days of spatially consistent extreme cold and warm days 

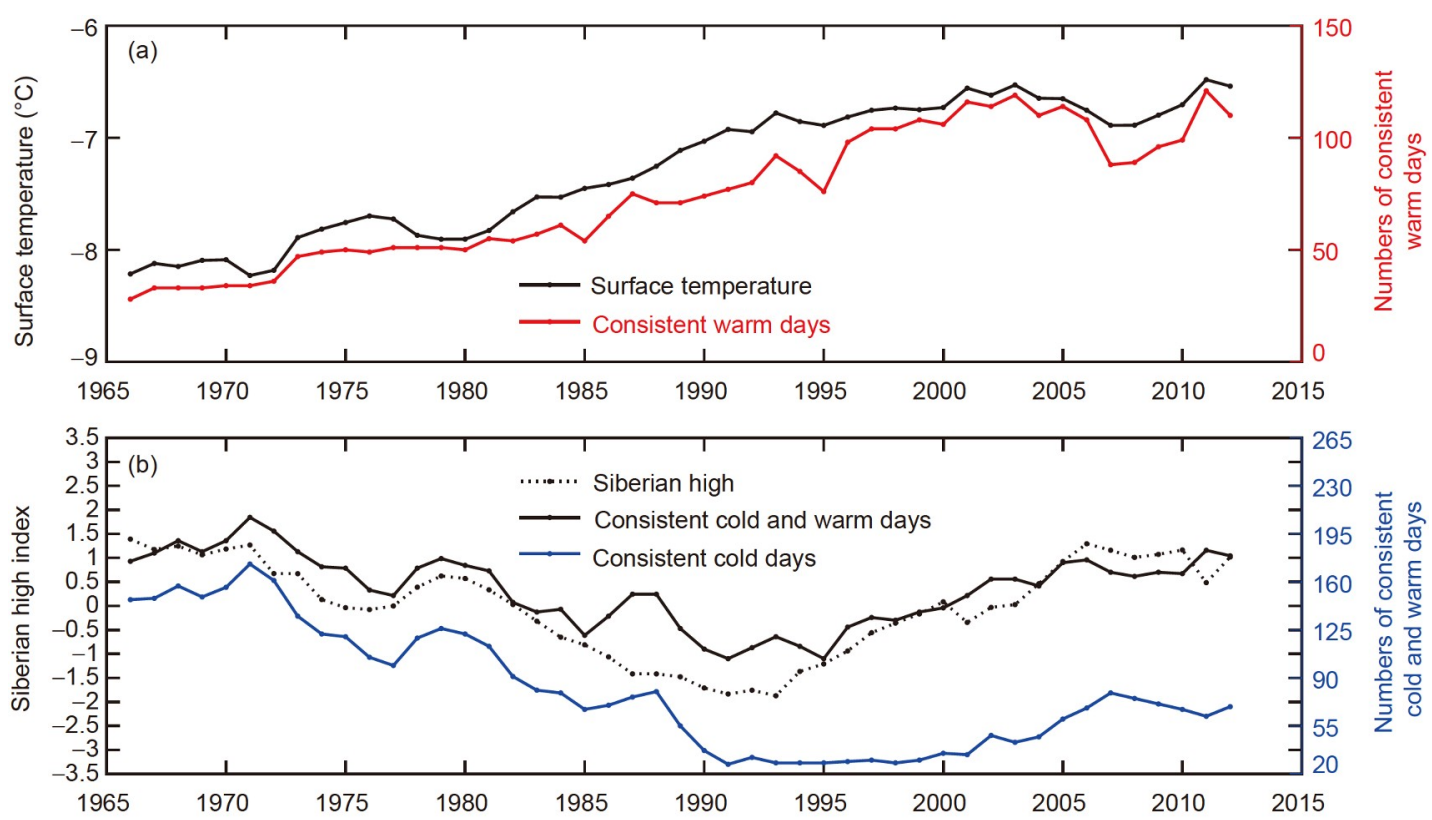

Figure 8 (a) Time series of the 11-year running spatially consistent extreme warm days and 11-yeara running mean winter SAT over China for 1961-2017; (b) Time series of 11-year running spatially consistent extreme cold days, the sum of the spatially consistent extreme cold and warm days, and the normalized Siberian High index of 11-year running mean for 1961-2017.
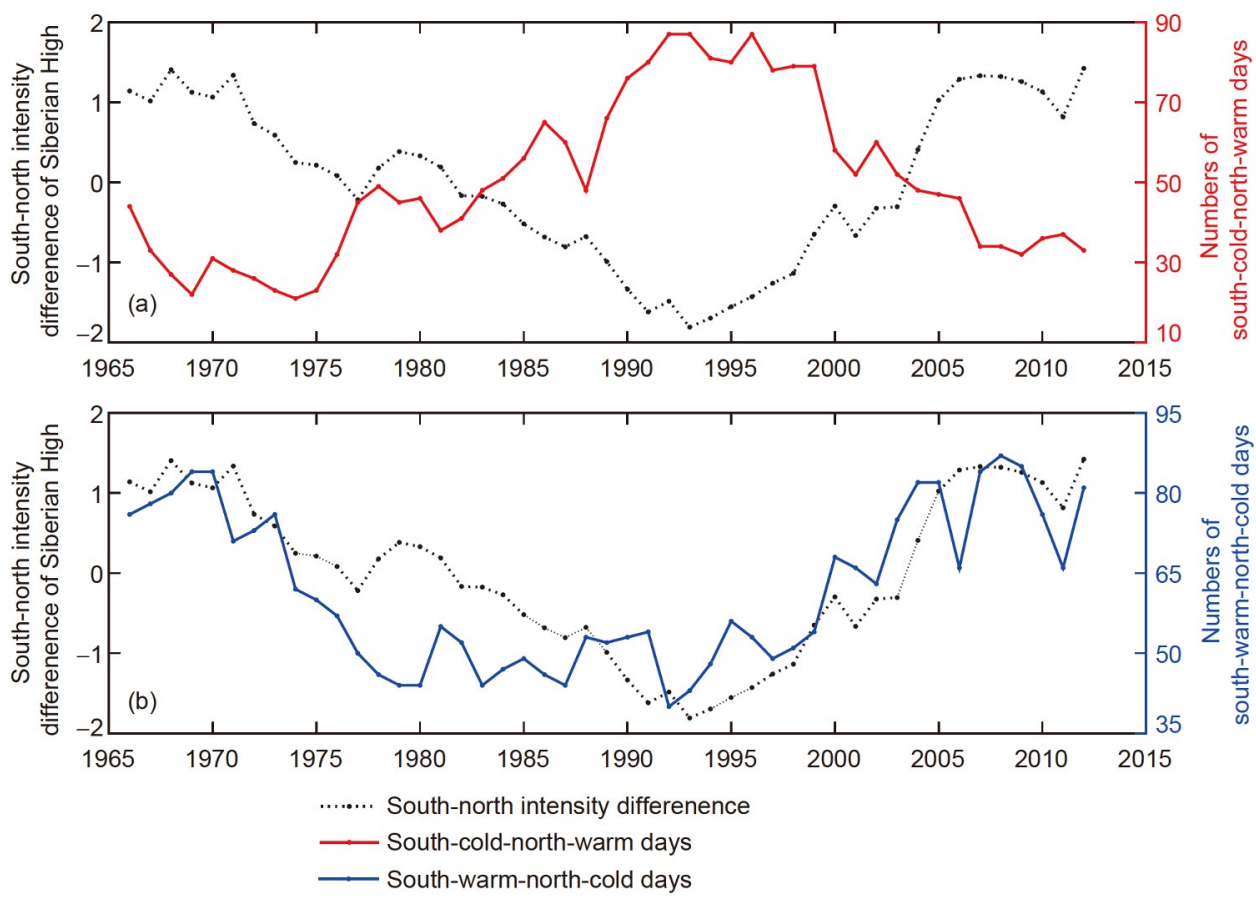

Figure 9 Time series of the 11-year running mean north-south difference of the SH index, (a) the 11-year running extreme south-warm-north-cold days and (b) extreme south-cold-north-warm days for 1961-2017.

after the 1990s is faster than the decreasing trend before the 1990s. The north-south movement of the SH center is consistent with the change of SH intensity, suggesting a faster increasing trend of the extreme south-warm-north-cold days after the 1990s than the decreasing trend before the 1990s. Note that the "cold Eurasia warm Arctic" mode also appeared in the late 1990s, so this mode may be closely related to SH intensity and location. The relevant driving factors need to be studied further.

\section{The North Atlantic meridional overturning circulation and the widespread extreme warm/ cold days}

The analysis above identifies the SH intensity and its north- 
south position as the key factors determining the occurrence of extreme cold and warm days. The SH is closely related to the thermal condition of Eurasia and the cold air in the Arctic, and the thermal changes of Eurasia and the Arctic are directly affected by the North Atlantic meridional overturning circulation (AMOC). Therefore, the AMOC may be the main driver of the extreme cold and warm days in China. Figure 10a shows the 11-year running average time series of the AMOC intensity index and the 11-year running numbers of the two types of extreme cold and warm days. The AMOC and the total occurrence days of the two types of extreme cold and warm days exhibit quite similar decadal variations. The gradual weakening of the AMOC before the 1990s is associated with a decrease in the total number of the two types of extreme cold and warm days while the gradual strengthening of the AMOC after the 1990s corresponds to an increasing number. The main difference between them is from 1985 to 1990 . The AMOC is in its weakest period while the total number of the two types of the extreme cold and warm days increases abruptly. In addition, the AMOC does not exhibit interannual fluctuations in the 1970s and 1980s, suggesting that the AMOC is the main driving factor of interdecadal change, but other factors have an impact on the occurrence of extreme cold and warm days on an interannual scale. Figure $10 \mathrm{~b}$ shows the time series of AMOC and the total occurrence days of the two kinds of extreme cold and warm days defined by $1.65(-1.65)$ standard deviations $(90 \%$ confidence level). The changes in the number of the two types of the extreme cold and warm days are basically similar whether 1.28 or 1.65 standard deviations are used to define the extreme cold/warm days, although the actual numbers differ, indicating that the definition of 1.28 standard deviations $(80 \%$ confidence level) used in this paper can represent the occurrence of the spatially consistent extreme cold and warm days in winter in China.

\section{Conclusions and discussion}

The leading two EOF modes of the SAT in December, January and February in China are characterized by a spatially country-wide coherent pattern and a north-south dipole pattern. Together they contribute $>50 \%$ of the SAT variance. Thus, the corresponding time series of the leading two modes are used to define the spatially consistent extreme warm/cold days and the extreme north-south dipole warm/cold days using a threshold of 1.28 standard deviations. The number of spatially consistent extreme warm days has increased in recent decades under global warming except around 2005. The spatially consistent extreme cold days decreased rapidly before the 1990s but increased in the late 1990s. The occurrence of extreme south-warm-north-cold days experienced a decreasing trend before the 1990s and an increase afterward, whereas the opposite is found for extreme south-cold-northwarm days. The spatially consistent extreme warm/cold days are associated with an in-phase SLP anomaly controlling the whole of China. The $500 \mathrm{hPa}$ geopotential height anomaly has a "- +" or "+ -" pattern from north to south and anomalous low-tropospheric in-phase southerly/northerly winds cover most of China. The extreme north-south dipole warm/cold days accompany out-of-phase SLP anomalies between the mid-high latitudinal Eurasia and mid-low latitudinal Eurasia. The $500 \mathrm{hPa}$ geopotential height anomalies exhibit a "+ - +" or " - + -" pattern from south to north and the anomalous meridional wind in the lower troposphere in Northeast China is opposite to that in southern China.
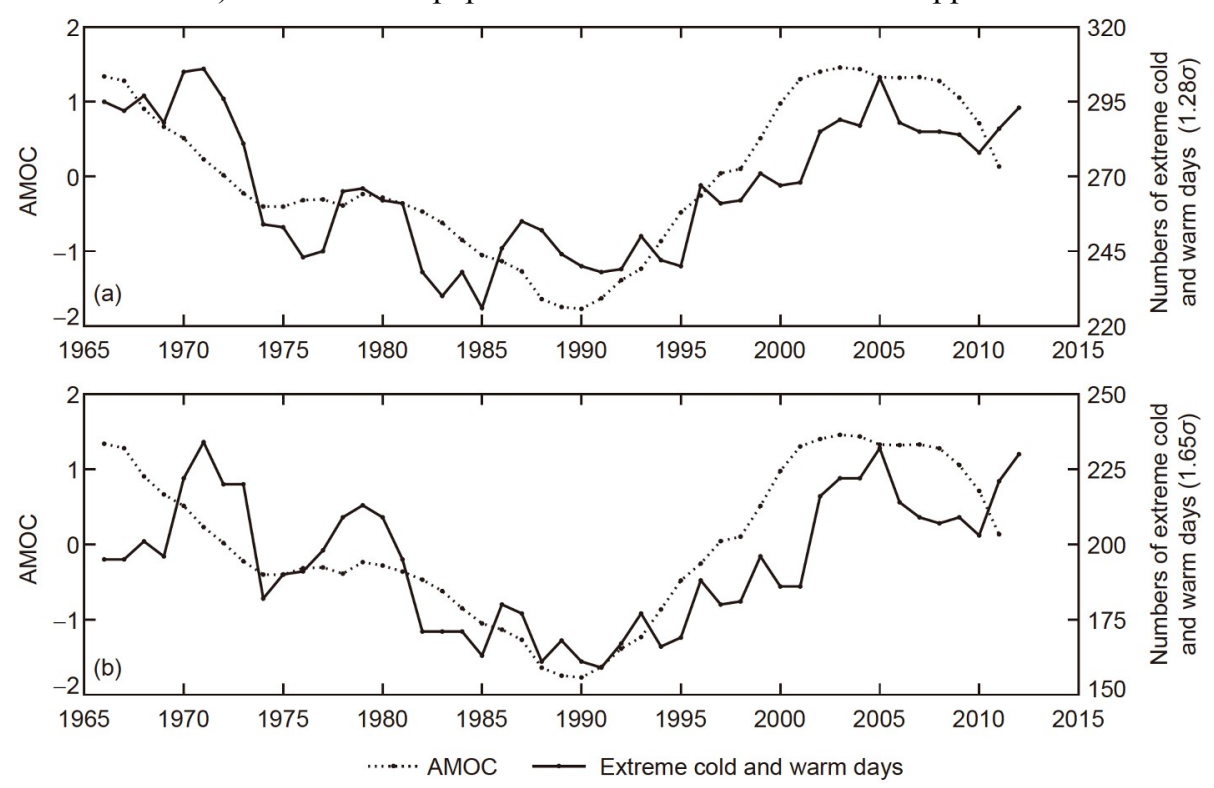

Figure 10 Time series of the AMOC index and the total number of the two types of extreme cold and warm days defined by (a) 1.28 standard deviations and (b) 1.65 standard deviations. 
With the warming of winter in China, the spatially consistent extreme cold days show a decreasing trend and their occurrence is concentrated from late December to early January, whereas the spatially consistent extreme warm days increase significantly in January and February. Nevertheless, the total number of spatially consistent extreme cold and warm days shows a similar time evolution to the SH intensity, indicating that the change of SH intensity is the key factor determining the sum of the extreme consistent cold and warm days. The effect of global warming changes the configuration of the spatially consistent extreme cold and warm days, but has little effect on their sum. The interdecadal variation of the north-south difference of the SH intensity is similar to that of the extreme south-warm-northcold days, but opposite to that of the extreme south-coldnorth-warm days. The smaller north-south difference of the SH intensity during 1980-2000 corresponds to a decrease in the number of extreme south-warm-north-cold days in winter in China, whereas the larger north-south difference before 1980 and after 2000 is associated with an increase of extreme south-cold-north-warm days.

Furthermore, the variation of the north-south difference of the SH intensity is basically consistent with that of the SH intensity. That is, when the SH is strong, the probability of $1028 \mathrm{hPa}$ appearing in mid-high latitudes is higher than that in mid-low latitudes or the SLP is higher in mid-high latitudes although the probability of $1028 \mathrm{hPa}$ appearing in mid-high latitudes is similar to that in the mid-low latitudes. When the center of anomalous high pressure is in the mid-high latitudes there are more extreme south-warm-north-cold days and extreme consistent cold days. When the SH is weak, the northsouth difference is small. The probability of the center of anomalous high pressure appearing in the mid-low latitudes become high, corresponding to more extreme south-coldnorth-warm days. Therefore, the SH strength is significantly related to the two types of extreme cold/warm days.

The SH is the main circulation system in mid-high latitude Eurasia in winter, and the AMOC is an important driver of the change of atmospheric thermal state in the mid-high latitudes of the Northern Hemisphere winter (Vellinga and Wood, 2002). The AMOC exhibits similar variations to those of the sum of the two types of extreme cold and warm days on interdecadal scales. The weakening AMOC during the 1960s to $1980 \mathrm{~s}$ is associated with the decrease in the sum of the two types of extreme warm days whereas the strengthening AMOC during the 1990s to 2010s corresponds to the increase in the sum of the two types of extreme warm and cold days. Thus, the AMOC is a driving factor of the total frequency of the two kinds of extreme cold and warm days in winter in China. The AMOC is closely related to the North Atlantic multidecadal oscillation and the North Atlantic Oscillation, but their relationship is complex. For example, some studies have pointed out that the AMOC and the North Atlantic multidecadal oscillation have a quarter phase difference, and the North Atlantic multidecadal oscillation modulates the change of the North Atlantic Oscillation, which has an important influence on the SH and the winter SAT in China. In addition, the AMOC can significantly influence Eurasian snow cover, Arctic sea ice and Pacific sea surface temperature, all of which are important factors related to the winter SAT in China. The westerly belt, the Ural blocking high and the East Asian Trough are the three key climate systems dominating the winter SAT in China. That is, the relationship between the AMOC, the SH and the extreme cold and warm days in winter in China is bound to be closely related to the Ural blocking high, East Asian Trough and westerly belt. The physical process for the influence of the AMOC on the occurrence frequency of the widespread extreme cold and warm days in winter in China is quite complex and needs to be investigated further (Mori et al., 2014; Luo et al., 2016; Wu et al., 2015, 2016, 2017; Johnson et al., 2018; Maroon et al., 2018; Chen and Tung, 2018; Zhang et al., 2019; Chen and Tung, 2021). If global warming caused by human activities causes significant weaking in the AMOC in the future (e.g. the accelerated melting of glaciers significantly weakening the AMOC), it may lead to a reduction of the frequency of extreme temperature events during winter in China.

Acknowledgements This work was supported by the National Key $R \& D$ Program (Grant No. 2016YFA0601502) and the National Natural Science Foundation of China (Grant Nos. 41822503 \& 41375092).

Open Access This article is licensed under a Creative Commons Attribution 4.0 International License, which permits use, sharing, adaptation, distribution and reproduction in any medium or format, as long as you give appropriate credit to the original author(s) and the source, provide a link to the Creative Commons licence, and indicate if changes were made. The images or other third party material in this article are included in the article's Creative Commons licence, unless indicated otherwise in a credit line to the material. If material is not included in the article's Creative Commons licence and your intended use is not permitted by statutory regulation or exceeds the permitted use, you will need to obtain permission directly from the copyright holder. To view a copy of this licence, visit http://creativecommons.org/licenses/by/4.0/.

\section{References}

Chen S F, Chen W, Wei K. 2013. Recent trends in winter temperature extremes in eastern China and their relationship with the Arctic Oscillation and ENSO. Adv Atmos Sci, 30: 1712-1724

Chen X Y, Tung K K. 2018. Global surface warming enhanced by weak Atlantic overturning circulation. Nature, 559: 387-391

Chen X Y, Tung K K. 2021. Comment on 'On the relationship between Atlantic meridional overturning circulation slowdown and global surface warming'. Environ Res Lett, 16: 038001

Chen Z, Wu R, Chen W. 2014. Distinguishing interannual variations of the northern and southern modes of the East Asian winter monsoon. J Clim, 27: 835-851

Ding Y H, Ren G Y, Zhao Z C, Xu Y, Luo Y, Li Q P, Zhang J. 2007. Detection, attribution and projection of climate over China (in Chinese). Desert Oasis Meteorol, 1: 1-10

Ding Y H, Liu Y J, Liang S J, Ma X Q, Zhang Y X, Si D, Liang P, Song Y 
F, Zhang J. 2014. Interdecadal variability of the East Asian winter monsoon and its possible links to global climate change. J Meteorol Res, 28: 693-713

Gong D Y, Wang S W. 1999. Long term variability of the Siberian high and the possibleconnection to global warming (in Chinese). Acta Geogr Sin, 54: $125-133$

Gong D Y, Wang S W, Zhu J H. 2001. East Asian winter monsoon and Arctic Oscillation. Geophys Res Lett, 28: 2073-2076

Guo Q Y. 1994. Relationship between the variations of East Asian winter monsoon and temperature anomalies in China (in Chinese). J Appl Meteorol, 5: 218-225

He S P, Wang H J. 2012. An integrated East Asian winter monsoon index and its interannual variability (in Chinese). Chin J Atoms Sci, 36: 523 $-538$

Hao Z X, Zheng J Y, Ge Q S, Ding L L. 2011. Variations of extreme cold winter events in southern China in the past 400 years (in Chinese). Acta Geogr Sin, 66: 1479-1485

Huang R H, Liu Y, HuangFu J L, Feng T. 2014. Characteristics and internal dynamical causes of the interdecadal variability of East Asian winter monsoon near the late 1990s (in Chinese). Chin J Atoms Sci, 38: 627 $-644$

Johnson N C, Xie S P, Kosaka Y, Li X. 2018. Increasing occurrence of cold and warm extremes during the recent global warming slowdown. Nat Commun, 9: 1724

Jolliffe I T. 1986. Principal Component Analysis. Springer-Ver-lag. 290

Kang L H, Chen W, Wei K. 2006. The interdecadal variation of winter temperature in China and its relation to the anomalies in atmospheric general circulation (in Chinese). Clim Environ Res, 11: 330-339

Kang L H, Chen W, Wang L, Chen L J. 2009. Interannual variations of winter temperature in China and their relationship with the atmospheric circulation and sea surface temperature (in Chinese). Clim Environ Res, 14: $45-53$

Liang S J, Ding Y H, Zhao N, Sun Y. 2014. Analysis of the interdecadal changes of the wintertime surface air temperature over mainland China and regional atmospheric circulation characteristics during 1960-2013 (in Chinese). Chin J Atoms Sci, 38: 974-992

Lim Y K, Kim H D. 2016. Comparison of the impact of the Arctic Oscillation and Eurasian teleconnection on interannual variation in East Asian winter temperatures and monsoon. Theor Appl Climatol, 124: 267-279

Liu J, Curry J A, Wang H, Song M, Horton R M. 2012. Impact of declining Arctic sea ice on winter snowfall. Proc Natl Acad Sci USA, 109: 40744079

Luo D H, Xiao Y Q, Diao Y N, Dai A G, Franzke C, Simmonds I. 2016. Impact of Ural blocking on winter warm arctic-cold Eurasian Anomalies. Part II: The link to the North Atlantic Oscillation. J Clim, 29: 3949-3971

Ma X Q, Ding Y H, Xu H M, He J H. 2008. The Relation between Strong Cold Waves and Low-Frequency Waves during the Winter of 2004/ 2005 (in Chinese). Chin J Atoms Sci, 32: 380-394

Maroon E A, Kay J E, Karnauskas K B. 2018. Influence of the Atlantic meridional overturning circulation on the Northern Hemisphere surface temperature response to radiative forcing. J Clim, 31: 9207-9224

Miao Q, Gong Y F, Deng R J, Wei N W. 2016. Impacts of the lowfrequency oscillation over the extra-tropics of the Northern Hemisphere on the extreme low temperature event in Northeast China in the winter of 2012/2013 (in Chinese). Chin J Atoms Sci, 40: 817-830

Mori M, Watanabe M, Shiogama H, Inoue J, Kimoto M. 2014. Robust Arctic sea-ice influence on the frequent Eurasian cold winters in past decades. Nat Geosci, 7: 869-873

Shen Z C, Ren G Y, Li J, Sun X B.2013. Winter temperature variability and its relationship with atmospheric circulation anomalies in Northeast China (in Chinese). J Meteorol Environ, 29: 47-54

Song L, Wu R. 2017. Processes for occurrence of strong cold events over
Eastern China. J Clim, 30: 9247-9266

Song L, Wu R. 2019. Combined effects of the MJO and the Arctic Oscillation on the intraseasonal eastern China winter temperature variations. J Clim, 32: 2295-2311

Shi N, Wang X, Tian P. 2019. Interdecadal variations in persistent anomalous cold events over Asian mid-latitudes. Clim Dyn, 52: 3729-3739

Vellinga M, Wood R A. 2002. Global climatic impacts of a collapse of the Atlantic thermohaline circulation. Clim Change, 54: 251-267

Wang B, Wu Z, Chang C P, Liu J, Li J P, Zhou T J. 2010. Another look at interannual-to-interdecadal variations of the East Asian winter monsoon: The northern and southern temperature modes. J Clim, 23: 1495-1512

Wang L, Chen W. 2014. The East Asian winter monsoon: Re-amplification in the mid-2000s. Chin Sci Bull, 59: 430-436

Wang L, Huang R, Gu L, Chen W, Kang L H. 2009. Interdecadal variations of the East Asian winter monsoon and their association with quasistationary planetary wave activity. J Clim, 22: 4860-4872

Wang L, Lu M M. 2017. The East Asian winter monsoon. In: Chang C P, ed. The Global Monsoon System: Research and Forecast. World Scientific. 51-61

Wang L, Zhang Q, Chen Y, Gong D Y. 2007. Changes of warmer winter and winter temperature over China in the Past 50 years (in Chinese). Clim Change Res, (1): 26-30

Wang X J, Gong Z Q, Ren F M, Feng G L. 2012. Spatial/temporal characteristics of China regional extreme low temperature events in winter during 1960-2009 (in Chinese). Clim Change Res, 8: 8-15

Wang X J, Gong Z Q, Shen B Z, Feng G L. 2013. A comparative study of the climatic characteristics of the periods of frequent occurrence of the regional extreme low temperature events in China in the recent 50 years (in Chinese). Acta Geogr Sin, 71: 1061-1073

Wu B Y, Su J Z, D'Arrigo R. 2015. Patterns of Asian winter climate variability and links to Arctic sea ice. J Clim, 28: 6841-6858

Wu B Y, Yang K, Francis J A. 2016. Summer Arctic dipole wind pattern affects the winter Siberian high. Int J Climatol, 36: 4187-4201

Wu B Y. 2017. Winter atmospheric circulation anomaly associated with recent Arctic winter warm anomalies. J Clim, 30: 8469-8479

Xiao D, Zuo Z Y, Zhang R H, Zhang X Y, He Q. 2017. Year-to-year variability of surface air temperature over China in winter. Int J Climatol, 38: 1692-1705

Xiao X, Chen W, Fan G Z, Zhou D W. 2016. Possible external forcing factors for the interdecadal change in the East Asian winter monsoon around the late 1990s (in Chinese). Clim Environ Res, 21: 197-209

Yang L N, Wu B Y. 2013. Interdecadal variations of the East Asian winter surface air temperature and possible causes (in Chinese). Chin Sci Bull, 58: 3969-3977

Yao S, Sun Q, Huang Q, Chu P. 2016. The 10-30-day intraseasonal variation of the East Asian winter monsoon: The temperature mode. Dyn Atmos Oceans, 75: 91-101

Zhang R N, Sun C, Zhang R H, Li W J, Zuo J Q. 2019. Role of Eurasian snow cover in linking winter-spring Eurasian coldness to the Autumn Arctic Sea ice retreat. J Geophys Res-Atmos, 124: 9205-9221

Zhang Z J, Qian W H. 2012. Precursors of regional prolonged low temperature events in China during winter half year (in Chinese). Chin J Atoms Sci, 36: 1269-1279

Zhou W, Li C Y, Wang X. 2007. Possible connection between Pacific Oceanic interdecadal pathway and east Asian winter monsoon. Geophys Res Lett, 34: L01701

Zhu Y F, Tan G R, Wang Y G. 2007. Variation of spatial mode for winter temperature in China and its relationship with the large scale atmospheric circulation (in Chinese). Clim Change Res, 3: 266-270

Zuo Z Y, Zhang R H, Huang Y, Xiao D, Guo D. 2015. Extreme cold and warm events over China in wintertime. Int J Climatol, 35: 3568-3581

Zuo Z Y, Yang S, Xu K, Zhang R H, He Q, Zhao T B, Cong J. 2018. Land surface air temperature variations over Eurasia and possible causes in the past century. Int J Climatol, 38: 1925-1937 